\title{
A ação construída na libras conforme a linguística cognitiva
}

\section{The constructed action in libras according to cognitive linguistics}

\section{Acción construida en libras según la lingüística cognitiva}

(iD) Elidéa Lúcia Almeida Bernardino

Universidade Federal de Minas Gerais (UFMG), Belo Horizonte, Minas Gerais, Brasil.

E-mail: elidea@ufmg.br

iD Dinalva Andrade Martins

Universidade Federal de Minas Gerais (UFMG), Belo Horizonte, MG, Brasil.

Email: dinalvaandrade@gmail.com

iD Jéssica Cristina Borba de Moura

Universidade Federal de Minas Gerais (UFMG), Belo Horizonte, Minas Gerais, Brasil. E-mail: jeyborba@gmail.com

iD Stéfanie Veríssimo Bastos

Universidade Federal de Minas Gerais (UFMG), Belo Horizonte, Minas Gerais, Brasil. E-mail: steverissimo@hotmail.com

Resumo: Este artigo descreve os resultados parciais de uma pesquisa sobre ação-construída (AC) em Libras, a partir de vídeos espontâneos de surdos, ou seja, vídeos de conteúdos diversos, disponibilizados pelos próprios sinalizantes em seus canais particulares na internet. Enfoca um dos elementos da representação da perspectiva, quando o sinalizante "incorpora" o referente, possibilitando a percepção dos fatos retratados sob a sua ótica. À luz da Linguística Cognitiva, busca-se compreender a relação entre a linguagem e o pensamento no uso discursivo. A AC é essencial para a compreensão dos enunciados pelos surdos, pois expressa uma riqueza de detalhes essenciais para o reconhecimento do referente. Quinto-Pozos (2007b) sugere que esse recurso seja obrigatório nas línguas de sinais. 
Palavras-chave: Línguas de Sinais. Libras. Ação construída. Perspectiva. Linguística Cognitiva.

Abstract: This paper partially describes the results of a research on constructed-action (AC) in Libras, from spontaneous videos of the Deaf available on the internet, that is, videos of various content, made available by the signers themselves on their particular channels. It focuses on one of the components of embodied perspective representation, when the signer "incorporates" the referent, allowing the perception of facts portrayed from his perspective. In the light of Cognitive Linguistics, we seek to understand the relationship between language and thought in discursive use. AC is essential for the comprehension of utterances by the deaf, as it expresses a wealth of substantial details for the referent's recognition. Quinto-Pozos (2007b) suggests that this feature is mandatory in sign languages.

Keywords: Sign language. Libras. Constructed action. Perspective. Cognitive Linguistics.

Resumen: Este artículo describe resultados de una investigación sobre Acción Construida (AC) en Libras, basada en videos espontáneos de sordos disponibles en Internet, es decir, videos de diversos contenidos, puestos a disposición por los propios señalizadores en sus canales particulares. Se enfoca en uno de los elementos de la representación en perspectiva, cuando hay "incorporación" del referente, permitiendo la percepción de elementos retratados desde su perspectiva. Por la linguística cognitiva, intentamos comprender la relación entre lenguaje y pensamiento en su uso. AC es esencial para la comprensión de los enunciados de los sordos, que expresa una gran cantidad de detalles para el reconocimiento del referente. Quinto-Pozos (2007) sugiere que esta característica es obligatoria en los lenguajes de señas.

Palabras clave: Lenguajes de señas. Libras. Acción construida. Perspectiva. Lingüística Cognitiva.

Submetido em 18 de abril de 2020.

Aceito em 11 de outubro de 2020.

Publicado em 08 de março de 2021. 


\section{Considerações iniciais}

O principal objetivo deste artigo é descrever os resultados parciais de uma pesquisa desenvolvida sobre a ação construída (AC) em Libras, a partir de vídeos espontâneos de surdos disponíveis na internet. Este artigo advém de um projeto que se propõe a registrar, descrever e analisar a forma como os surdos representam a AC em discursos espontâneos na Libras e como o ponto de vista interfere na construção desse recurso. Como parte do projeto principal, que analisa a perspectiva em Libras, o trabalho enfoca um dos elementos da representação da perspectiva no discurso, que é quando o sinalizante "incorpora" o referente, assumindo sua postura, seus trejeitos e seu modo de agir. Esse recurso é frequentemente encontrado nas diversas línguas de sinais, tendo sido observado também em diálogos construídos, especialmente em narrativas, em línguas orais. É utilizado pelo falante na demonstração do fato narrado, possibilitando a percepção de fatos retratados sob sua ótica.

A abordagem teórica seguida é da Linguística Cognitiva, buscando compreender a relação entre a linguagem e o pensamento através da análise de construções linguísticas no seu uso. É perceptível quando algumas pessoas, ao relatarem a fala de uma terceira, mudam a tonalidade da voz e realizam até mesmo uma postura caricatural para descrever melhor aquela fala. O surdo realiza esta mesma ação de inserir a fala, o enunciado ou as ações de outra pessoa no discurso, alterando de forma bastante peculiar a expressão corporal e facial.

Foram selecionados vídeos em Libras cujos sinalizantes são conhecidos do público por meio do YouTube e que utilizam gêneros textuais variados: piadas, narrativas, entrevistas, depoimentos. Todos os sinalizantes dos vídeos selecionados são surdos que usam preferencialmente a Libras como primeira língua, aparentemente com pouca influência da língua portuguesa em sua sinalização. Os vídeos apresentam uma média de tempo entre 3 e 12 
A ação construída na libras conforme a linguística cognitiva

Elidéa Lúcia Almeida Bernardino - Dinalva Andrade Martins • Jéssica Cristina Borba de Moura • Stéfanie Veríssimo Bastos

minutos. Todas as ACs foram marcadas, analisadas e comparadas umas com as outras em relação à realização e contexto. Esses vídeos foram analisados utilizando-se o ELAN Linguistic annotator, que é uma ferramenta de análise de vídeos que permite criar, editar, visualizar e buscar dados específicos nos vídeos. Foi desenvolvido pelo Max Planck Institute e é disponibilizado gratuitamente pelo próprio Instituto.

Após as análises individuais de cada vídeo, os resultados foram discutidos com o grupo de pesquisadores - a professora autora do projeto e as três bolsistas de Iniciação Científica - a fim de se registrar a pesquisa. O uso da AC é extremamente importante para a compreensão dos enunciados pelos surdos, pois expressa uma riqueza de detalhes essenciais para o reconhecimento do referente. Alguns autores (como QUINTO-POZOS, 2007b) chegam a sugerir que o uso desse recurso seja obrigatório nas línguas de sinais em certos momentos. A perspectiva teórica adotada será apresentada no referencial teórico a seguir, seguindo-se os métodos utilizados e a discussão dos resultados.

\section{Referencial teórico}

A abordagem cognitivista percebe a aprendizagem como uma construção contínua do conhecimento por meio das interações com o outro e com o mundo. Essa abordagem busca compreender a relação entre a linguagem e o pensamento através da análise das construções linguísticas no seu uso. Ela parte de dois princípios:

A perspectiva cognitiva da gramática fundamenta-se em dois princípios, correspondentes ao reconhecimento de duas funções básicas da linguagem: o princípio de que a linguagem é um sistema simbólico do próprio processo de conceptualização e o princípio de que a linguagem é um meio de comunicação/interacção. (SILVA; BATORÉO, 2010, p. 230, grifos do autor). 
Para a Linguística Cognitiva, o conhecimento linguístico não pode ser separado do conhecimento de mundo, assim como o conhecimento semântico não pode ser separado do conhecimento pragmático. Diversamente ao modelo gerativista, a Linguística Cognitiva adota a hipótese de que a linguagem não é modular, mas que os diferentes "módulos" da linguagem partilham traços fundamentais de organização (FERRARI, 2011). O estabelecimento da referência, por exemplo, é definido com base na Teoria dos espaços mentais (FAUCONNIER, 1994, 1997 apud FERRARI, 2011). Conforme essa teoria, espaços mentais são criados à medida que o discurso se desenvolve. $\mathrm{O}$ espaço que fundamentaria o discurso no momento de sua ocorrência seria a BASE, e a partir dela outros espaços mentais seriam criados para falar de outras informações que extrapolem o contexto imediato.

Ferrari (2011) cita Cutrer (1995) ao apontar o papel do tempo e modos verbais na construção e estruturação de espaços mentais. São indicados quatro princípios de organização discursiva: base, foco, evento e ponto de vista. A base seria o centro de referência, sendo o ponto de partida da conceptualização e indicando o tempo presente. $O$ foco seria o espaço onde o significado está sendo construído, sendo o espaço ao qual a sentença se refere. 0 evento seria o espaço temporal onde a codificação do verbo ocorre e o ponto de vista seria o centro da conceptualização e consciência do self (normalmente, o falante), a quem a sentença seria outorgada. Normalmente, o ponto de vista coincide com a perspectiva, ou o ponto de vantagem, o lugar de onde o falante se coloca ao descrever uma cena vista ou narrada.

A descrição das ações de uma pessoa pode ser feita utilizando-se diferentes perspectivas. Perniss (2007) aponta duas formas diferentes de representação espacial da perspectiva em línguas de sinais. Elas são diferenciadas pelo tipo de informação expressa, pelo tamanho do evento retratado e do ponto de vista utilizado para a representação do referente. Em uma das formas de representação, o sinalizante é visto como fazendo parte do evento, atuando como um personagem. No papel de personagem, o si- 
nalizante constrói as ações e atitudes atribuídas ao personagem, utilizando o seu próprio corpo. O evento é definido numa escala de tamanho real, assim como o espaço em volta do sinalizante. Esse é um tipo de evento descrito por Perniss (2007) como "perspectiva do personagem". A outra forma de representação espacial é chamada de "perspectiva do observador". Nessa perspectiva, o sinalizante localiza-se conceptualmente fora do evento, como um observador externo. Ele atuaria como um manipulador de marionetes, controlando os personagens numa escala reduzida em frente ao seu corpo, onde o evento é construído.

Stec (2012) dá um exemplo que deixa claras essas três formas de representação: imagine que você está caminhando em uma rua e vê uma pessoa descendo de paraquedas em um campo gramado à sua frente. De repente, um objeto bate no paraquedas e a pessoa começa a cair. Porém, essa pessoa consegue reassumir o controle do paraquedas e descer em segurança bem à sua frente. Quando você for relatar o fato, você o fará conforme a sua própria perspectiva (como se estivesse vivenciando a queda), sob a perspectiva de uma pessoa que assiste à queda ou em ambas? Isso vai depender, porque haverá momentos em que você poderá usar o seu próprio corpo para demonstrar como o paraquedista se assustou com o provável acidente, como ele manejou o paraquedas para retomar o controle; outras vezes você poderá usar gestos para identificar o objeto batendo no paraquedas ou a trajetória do paraquedas caindo e, ainda, você também poderá apresentar os pontos de vista misturados. Ao usar o seu próprio corpo na narrativa, o falante adota a perspectiva do personagem; ao narrar um fato observado, como o objeto batendo no paraquedas, a perspectiva do observador é utilizada e, ao misturar as perspectivas, como demonstrando a expressão facial do paraquedista e na mão direita um gesto de algo vindo em sua direção e acertando o paraquedas, utiliza-se uma perspectiva mista.

Na utilização da língua oral acompanhada de gestos, o falante carrega na fala a ênfase da informação e da transmissão das suas emoções. Os gestos são utilizados concomitantes à fala, acrescen- 
tando a ela elementos que complementarão o conteúdo informado. Nas línguas de sinais, embora também sejam utilizados gestos concomitantes à "fala" sinalizada, o canal utilizado por ambos (sinais e gestos) é o mesmo. Por esse motivo, algumas pessoas chegam a pensar que as ações construídas, por exemplo, sejam gestos concomitantes à sinalização. Entretanto, diversas pesquisas vêm demonstrando que são coisas distintas (DUDIS, 2006; QUINTO-POZOS, 2007a; 2007b; ÖZYÜREK; PERNISS, 2011; STEC, 2012; QUINTO-POZOS; PARRIL, 2015). Uma ação construída, diferentemente de gestos espontâneos, segue uma série de regras que delimitam a sua elaboração. Como exemplo, um sinalizante, ao narrar uma pessoa saltando de uma rampa em uma piscina ou num lago, representa em seu corpo e face a pessoa correndo pelo movimento dos braços, pernas e postura corporal, entretanto sem se deslocar numa corrida real. Os movimentos da corrida são expressos em seu rosto e corpo, porém o deslocamento deve ser feito utilizando-se um classificador de entidade. Classificadores seriam configurações de mãos usadas em verbos de movimento ou de localização, para demonstrarem um referente (BERNARDINO, 2012).

Ao executar uma AC, o sinalizante assume a perspectiva do personagem e encena a ação (QUINTO-POZOS; PARRIL, 2015). Isso pode ser feito usando todo o corpo, a cabeça e o tronco, ou apenas a cabeça, para demonstrar expressões afetivas de um personagem (por exemplo, humor ou emoções). Durante a AC, o corpo do referente é mapeado no corpo do sinalizante. Ele pode alternar as perspectivas, utilizando ora a perspectiva do personagem, ora a do observador, ora uma perspectiva mista. Ao retratar a perspectiva do observador, o sinalizante utiliza classificadores.

Supalla (1986) afirma que os classificadores são morfemas utilizados em verbos de movimento e de localização, sendo que cada um dos parâmetros básicos usados nesses verbos é um morfema. Para Supalla (1986), haveria cinco tipos de classificadores, que seriam: (1) CL semânticos; (2) CL de corpo; (3) CL de partes do corpo; (4) $\mathrm{CL}$ de instrumento e (5) especificadores de tamanho e forma. 
Em nossas pesquisas, consideramos que classificadores são as configurações de mãos utilizadas para representar um referente na perspectiva do observador. Eles seriam divididos em quatro tipos: (1) CL de entidade (correspondendo ao semântico); (2) CL de manuseio (instrumento); (3) CL descritivos (especificadores de tamanho e forma) e (4) CL de partes do corpo. O que Supalla (1986) considera o $\mathrm{CL}$ de corpo as pesquisas mais atuais têm identificado como sendo a AC, ou seja, o sinalizante utiliza o próprio corpo para projetar o referente.

Diferentemente da forma como um falante de línguas orais utiliza o seu corpo ao demonstrar a perspectiva do referente, o sinalizante precisa seguir certas regras. Uma delas seria que o sinalizante não se desloca durante uma $\mathrm{AC}$, mesmo que ele queira demonstrar, por exemplo, que o referente está correndo, como apontado anteriormente. Ao demonstrar uma pessoa que caminha com uma mochila aos ombros, o sinalizante evidencia a pessoa carregando a mochila no próprio corpo, enquanto o deslocamento é feito através de um $\mathrm{CL}$ de entidade, que mostra o deslocamento feito por essa pessoa. Se pensarmos nessas cenas como em um filme, na AC a câmera daria ênfase na pessoa, mostrando-a em destaque, ocupando grande parte da tela (como um close-up ou zoom-in de uma câmera); o classificador de entidade representaria a mesma pessoa de corpo inteiro, mais distante, numa perspectiva reduzida (como um zoom-out da câmera), como se alguém a estivesse vendo de longe. Porém, as duas cenas seriam apresentadas ao mesmo tempo, na mesma tomada. Veja, na Figura 1, o exemplo de uma pessoa caminhando com uma mochila nas costas. Observe que, na mão direita, o sinalizante apresenta a pessoa se deslocando - configuração de mão (CM) U-invertido -; enquanto a face e o tronco marcam a expressão facial e corporal da pessoa, e a mão esquerda marca a pessoa segurando a alça da mochila. 


\section{Figura 1 - Relato de uma pessoa caminhando com uma mochila às costas - Imagem do surdo Rainer Nonato}

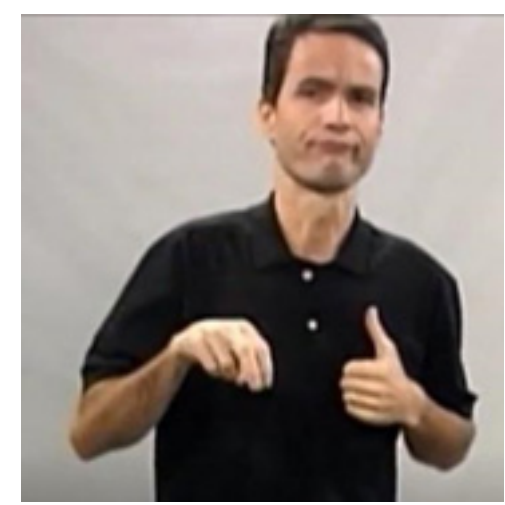

Fonte: acervo pessoal, utilizada com autorização. Extraída do vídeo "Perdi minha mochila" (UFMG - 02 mar. 2010) em 09 jun. 2017.

Nesse tipo de AC, em que são evidenciadas a expressão facial e corporal do personagem, além do seu deslocamento no espaço, ocorre o particionamento do corpo. Significa que, enquanto o sinalizante assume a perspectiva de um personagem em seu rosto ou no rosto e tronco, uma de suas mãos toma a perspectiva de um observador, podendo representar o mesmo referente do rosto ou um referente diferente, utilizando um classificador (BERNARDINO, 2012). Na figura acima, tem-se a representação do mesmo referente em duas perspectivas diferentes: na face e corpo temos uma AC e na mão direita um $C L$ de entidade. Com o particionamento do corpo, o sinalizante assume uma perspectiva mista, ou seja, no rosto e tronco teríamos um referente que estaria vivenciando o espaço real da narrativa, assim como o tempo da narrativa. A perspectiva retratada no corpo e rosto do sinalizante seria a do personagem. Em uma de suas mãos, entretanto, teríamos a perspectiva do observador, ou daquele que observa a cena narrada. Como ambos os espaços mentais se misturam, teríamos, então, uma perspectiva mista (QUINTO-POZOS; PARRIL, 2015; DUDIS, 2006).

Dudis (2006) explica essa mistura de espaços mentais usando a teoria de mistura conceitual de Fauconnier e Turner (1996). Enquanto o sinalizante mantém um espaço mental ativo com a AC 
A ação construída na libras conforme a linguística cognitiva

Elidéa Lúcia Almeida Bernardino - Dinalva Andrade Martins • Jéssica Cristina Borba de Moura • Stéfanie Veríssimo Bastos

(ou incorporação do personagem), ele pode utilizar uma das mãos para demonstrar o mesmo personagem em outro espaço mental (através de um classificador) e na outra mão ainda pode haver um outro referente (usando outro classificador). Dudis (2006) apresenta o relato de um motociclista em que o sinalizante incorpora o personagem em seu próprio corpo, enquanto numa das mãos é demonstrada a motocicleta e na outra a superfície inclinada (um morro, indicando que a moto está subindo o morro). Exemplificamos com uma cena semelhante, descrita pelo surdo Rainer Nonato na Figura 2. Observe que em (a), na mão esquerda, o sinalizante apresenta a moto, usando a configuração de mão "B" (CM B); na direita, o motociclista (CM V-invertido); enquanto a face e o tronco mantêm o motociclista. Em (b) temos a figura de uma motocicleta na mesma perspectiva representada; em (c) a mão esquerda do sinalizante segura a manete (guidão), a mão direita indica o velocímetro (seta indicando a trajetória do movimento do velocímetro), enquanto a sua face e tronco mantêm o motociclista ativo.

Figura 2 - Exemplo de um relato de um motociclista
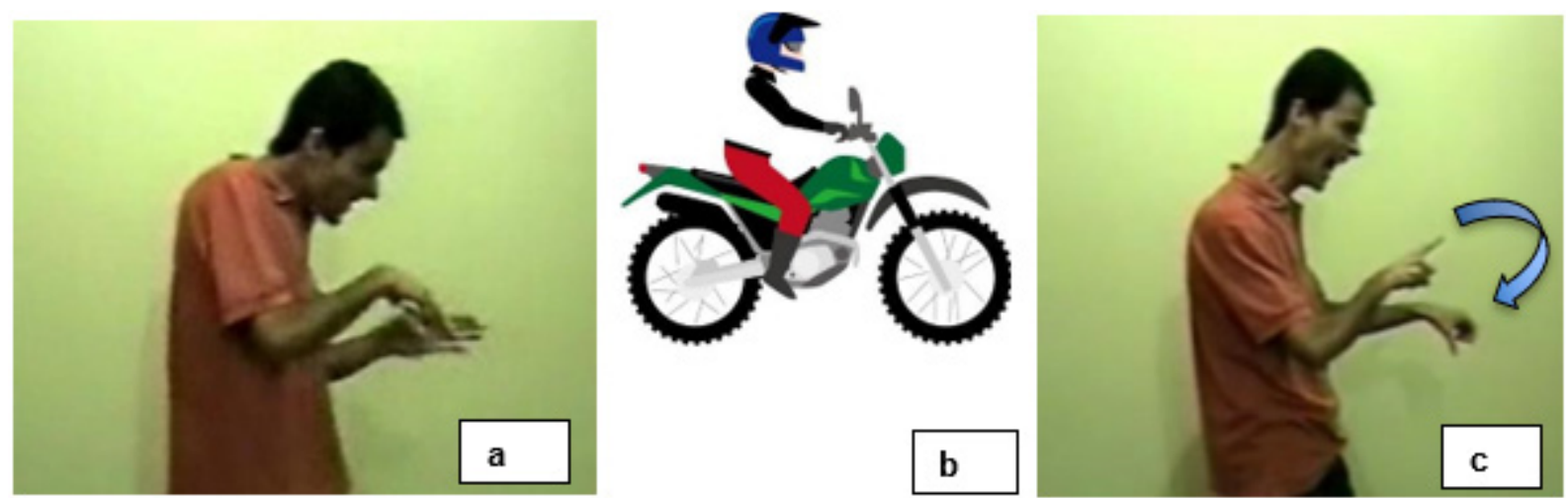

Fonte: Imagens (a) e (c) - acervo pessoal, utilizadas com autorização. Imagem extraída em 09 jan. 2017 do vídeo "Motoqueiro" (acervo pessoal da primeira autora, de 25 ago. 2008).

Imagem (b) - Clipart de uso gratuito, disponível em clipart-library.com (Free Clip Art).

É interessante que na AC o narrador é o único elemento visível no espaço conceptual. A motocicleta, na primeira imagem, assim como a manete e o velocímetro, na terceira imagem, não são elementos visíveis na narrativa. Eles tornam-se perceptíveis pela utilização dos classificadores. Observe que é possível perceber 
uma certa semelhança entre a primeira imagem - classificadores de entidade, representados pela configuração de mão (CM) "B" na mão esquerda, demonstrando a moto, e CM "V-invertido", demonstrando o corpo, ou as pernas do motociclista sobre a moto - e a segunda imagem (figura da moto, na mesma perspectiva). Da mesma forma, na terceira imagem, o sinalizante utiliza na mão direita um outro classificador de entidade (CM "1") para representar o ponteiro do velocímetro movendo-se, indicando aumento da velocidade da moto (representada na Figura 2, imagem c), enquanto um classificador de manuseio na mão esquerda mantém a mão do motociclista segurando o guidão da moto.

Quinto-Pozos (2007a) aponta que a entonação de línguas orais e uma AC (que ele denomina nesse artigo como "tornar-se o objeto", uma vez que na AC o sinalizante age como se fosse o objeto referenciado) parecem semelhantes em alguns aspectos, mas bastante diferentes em outros. Entre as semelhanças, ele afirma que através da AC o sinalizante pode prover várias informações afetivas sobre um personagem (como, por exemplo, humor, emoções e distinções como estar relaxado ou apressado), o que pode também ser fornecido pela entonação nas línguas orais. Entretanto, parece haver diferenças importantes entre esses dois recursos. Uma delas é que uma gama de informações é provida pelas AC, mas não podem ser fornecidas pela entonação. Algumas delas seriam as ações realizadas, a forma do movimento, tamanho relativo do referente e a sua postura. Também não é possível, pela entonação, demonstrar como o referente interage com outros objetos - o que é possível ser fornecido pela AC.

Stec (2012) aponta outro importante elemento na AC que torna esse recurso ainda mais peculiar. A autora faz um estudo comparativo entre gestos utilizados concomitantes à fala com ações construídas (AC) e classificadores (CL) de línguas de sinais. Ela caracteriza os gestos corporais que o falante utiliza ao agir como se fosse o personagem narrado, como "ponto de vista do personagem" - CVPT, e os gestos manuais utilizados, com algumas características semelhantes às dos $C L$ das línguas de sinais, como 
"ponto de vista do observador" - OVPT. Stec (2012) observou que, tanto na AC quanto na CVPT, a direção do olhar indica transição de um ponto de vista conceitual para outro, ou de um espaço mental para outro. Quando combinada com a mudança de orientação do corpo, a direção do olhar pode indicar a perspectiva do personagem. Esse elemento mostrou-se relevante em nossas análises, o que será relatado na metodologia e na análise dos resultados.

\section{Metodologia}

\subsection{Seleção dos vídeos}

Foram analisados nove vídeos extraídos de perfis do YouTube de alguns surdos conhecidos na Comunidade surda brasileira. Apesar de os vídeos estarem disponíveis e serem públicos, entramos em contato com cada um deles e solicitamos autorização para analisarmos os vídeos com fins de pesquisa. Todos foram autorizados, entretanto apenas seis foram selecionados e trabalhados. Os vídeos foram assistidos integralmente em um primeiro momento, sendo posteriormente observada a ocorrência e a frequência das ACs nas sinalizações. As ACs foram analisadas frame a frame (recurso disponibilizado pela ferramenta ELAN), e sucessivamente identificadas e classificadas de acordo com a sua localização no corpo do sinalizador. Cada vídeo foi assistido e revisado por um outro pesquisador e depois levado para todas as autoras para verificação e discussão dos resultados obtidos individualmente. Apenas depois de validado pelo grupo o trabalho seguiu para descrição em texto acadêmico. A seleção ocorreu visando uma análise mais aprofundada dos vídeos em que havia mais ocorrências de AC. Por não conterem um número significativo de AC que poderiam ser analisadas, os outros três vídeos foram descartados. A identificação dos vídeos escolhidos encontra-se na Tabela 1. 
A ação construída na libras conforme a linguística cognitiva

Elidéa Lúcia Almeida Bernardino - Dinalva Andrade Martins • Jéssica Cristina Borba de Moura •

Stéfanie Veríssimo Bastos

Tabela 1 - Identificação dos vídeos analisados

\begin{tabular}{|c|c|c|c|}
\hline Vídeo & & Autor/site & Gênero textual \\
\hline I & A Mulher de Samaria & Rainer Nonato & $\begin{array}{l}\text { Contação de história (narra- } \\
\text { tivo) }\end{array}$ \\
\hline I & $\begin{array}{l}\text { Piada do avião com um surdo e ou- } \\
\text { vintes }\end{array}$ & Andrei Borges & Piada (narrativo) \\
\hline 1 & $\begin{array}{l}5 \text { Coisas que todo mundo gosta me- } \\
\text { nos eu! }\end{array}$ & Léo Viturinno & Texto de opinião (informal) \\
\hline I & Falando sobre direito em Libras. & Sandro Santos & $\begin{array}{l}\text { Texto argumentativo (infor- } \\
\text { mal) }\end{array}$ \\
\hline I & Os surdos têm voz & Leonardo Castilho & Testemunho (denúncia) \\
\hline \multicolumn{2}{|c|}{ Gente que inspira } & Leonardo Castilho & Entrevista \\
\hline
\end{tabular}

\subsection{Instrumentos de análise e procedimentos}

Os vídeos foram analisados utilizando-se o ELAN, um programa que possibilita análise de arquivos de áudio e vídeo, desenvolvido pelo Instituto Max Planck de Psicolinguística. Sua utilização permite a descrição de movimentos corporais relacionados às ACs, com possibilidade de criação de diversas trilhas. Além disso, o programa é gratuito, sendo assim bastante utilizado pelos estudiosos das línguas de sinais.

Foram criadas oito trilhas para a análise dos vídeos: (a) tradução; (b) mão dominante; (c) mão não dominante; (d) direção do olhar; (e) ponto de vista; (f) descrição da AC; (g) AC tipos; (h) classificadores.

A trilha "tradução" identifica em português os trechos realizados em língua de sinais; assim, busca-se uma palavra ou frase em português e visualiza-se na Libras ou vice-versa. As trilhas "mão dominante" e "mão não dominante" são importantes para a análise de classificadores, pois os sinalizantes podem apresentar diferentes referentes em ambas as mãos. A mão dominante seria a mão principal, ou seja, a mais utilizada pelo sinalizante e a não dominante seria a menos usada, a de apoio. Entretanto, diferen- 
temente das regras de elaboração de sinais, nos classificadores as duas mãos carregam conteúdo, podendo, inclusive, indicar referentes diferentes, conforme especificado acima. A trilha "direção do olhar" identifica se o olhar se direcionava para fora (para o interlocutor ou para a câmera) ou para dentro da cena (como se o sinalizante estivesse vivenciando o personagem), e assim identificar as perspectivas do narrador, do personagem ou mista.

Caso o olhar estivesse direcionado para fora da cena, ou seja, para o interlocutor presente no espaço real de sinalização, como na entrevista de Leonardo Castilho (Figura 9 [b]), por exemplo, ou o olhar estivesse direcionado para a câmera, como na narrativa de Andrei (Figura 5 [a]), a marcação adotada seria "para fora". Nesse caso, a perspectiva adotada seria a de narrador - é a perspectiva do sujeito que narra a história. Caso o olhar estivesse direcionado para dentro da cena, ou seja, o sinalizador estaria personificando o personagem, como Rainer Nonato (Figura 4 [c]), a perspectiva adotada seria a do personagem. Na identificação da perspectiva mista, teríamos o sinalizante narrando uma história, com o olhar voltado para dentro da cena; em dado momento, esse olhar se volta para a câmera (em flashes bem rápidos), retornando em seguida para dentro da cena. Seria uma forma de o sinalizante fazer um contato visual com o seu interlocutor (no caso, a câmera) para certificar-se de que ele/ela estaria acompanhando a narrativa. Isso pode ser entendido pela função fática da linguagem, quando o falante utiliza termos como "você entendeu?", por exemplo, certificando-se que o interlocutor continua atento à sua mensagem. As trilhas "descrição da AC" e "AC tipos" descrevem a ação realizada pelo sinalizante e o tipo de AC utilizada, indicando se somente a cabeça, se a cabeça e o tronco ou um classificador era também utilizado. Finalmente, a trilha "classificadores" era utilizada para marcar os tipos de $\mathrm{CL}$ presentes na narrativa. 


\section{Figura 3 - Exemplo de uma tela de trabalho no ELAN}

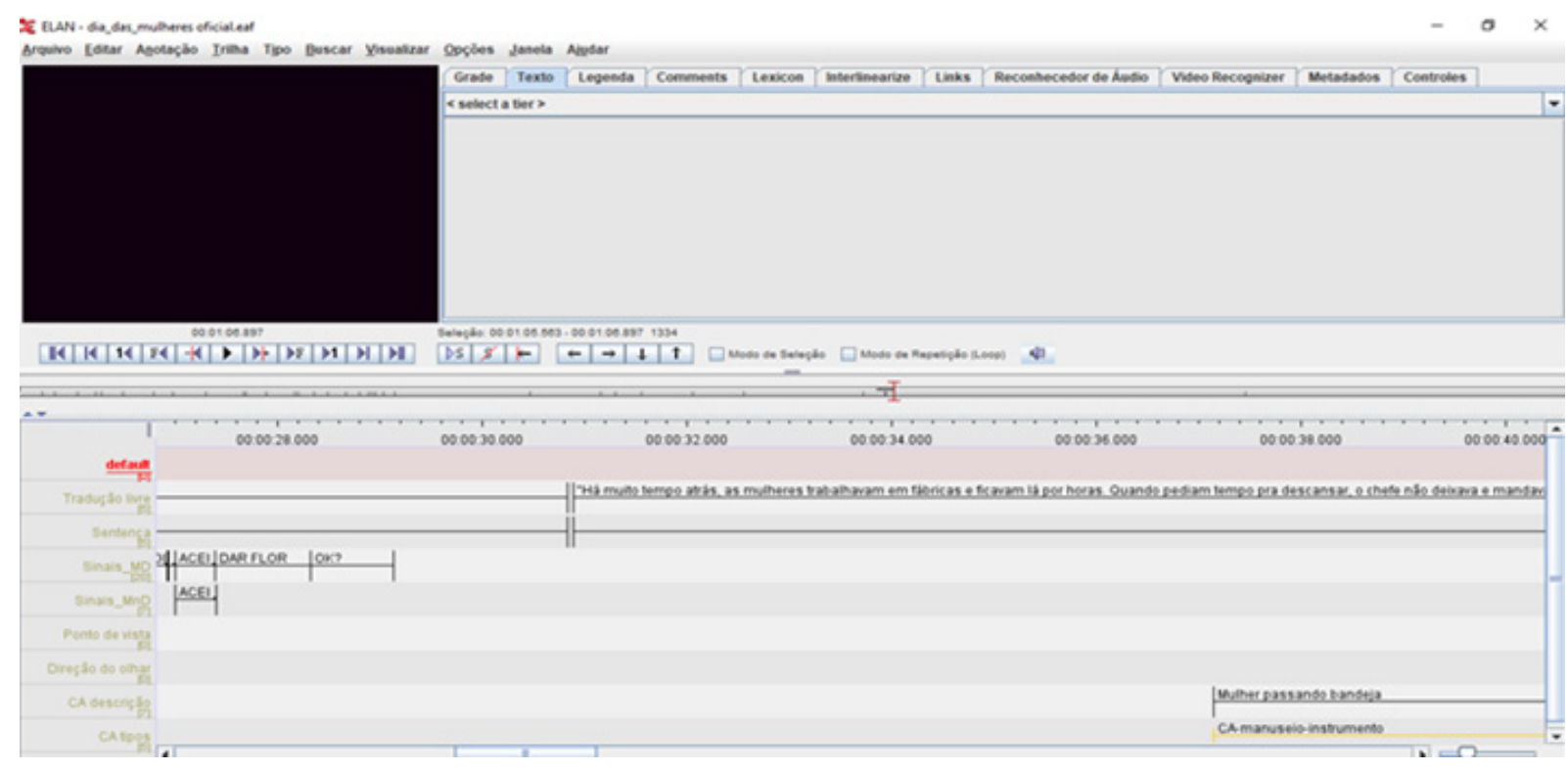

Fonte: Arquivo pessoal, gerada a partir de um em print de tela em 27 fev. 2018.

\section{Análise e resultados}

Inicialmente foram analisados vídeos de contação de histórias e piadas, objetivando perceber quais ações construídas são utilizadas e com que frequência. O primeiro vídeo analisado é "A mulher de Samaria", uma narrativa feita pelo professor surdo de Libras, Rainer Nonato, com o propósito de divulgar histórias bíblicas para pessoas surdas. Foi selecionada a parte do diálogo de Jesus com uma mulher samaritana.

Durante a narrativa, o sinalizante olha diretamente para a câmera, interagindo com o espectador. No momento das falas dos personagens, o sinalizante passa a incorporá-los, desviando seu olhar da câmera, como se estivesse visualizando a cena internamente, realizando a AC. O olhar do sinalizante/narrador é alternado ora para a câmera e ora para o outro personagem, marcado na cena pela sua localização - à sua esquerda ou à sua direita. As expressões facial e corporal são essenciais nesse processo de incorporação, uma vez que o sinalizante ora assume o seu papel de 
A ação construída na libras conforme a linguística cognitiva

Elidéa Lúcia Almeida Bernardino • Dinalva Andrade Martins • Jéssica Cristina Borba de Moura • Stéfanie Veríssimo Bastos

narrador - narrando a história aos seus interlocutores e interagindo com eles através do seu olhar voltado para a câmera (Figura 4 [a]) - ora assume o papel da mulher samaritana (Figura 4 [b]), ora o de Jesus (Figura $4[c]$ ).

O uso do espaço, assim como as expressões faciais e corporais, contribuem para a identificação do personagem incorporado. Jesus sempre é incorporado com uma leve inclinação para a direita do sinalizante (como se a mulher estivesse à sua esquerda na cena narrada), enquanto a mulher samaritana é incorporada com uma inclinação para a esquerda, construindo o cenário. O direcionamento do olhar volta-se para dentro da cena quando o sinalizante incorpora os personagens e para a câmera quando o papel de narrador está ativo. Identificamos 68 situações de AC nessa narrativa, que durou 10:58 minutos.

Figura 4 - Imagens extraídas do vídeo “A Mulher de Samaria”, de Rainer Nonato.

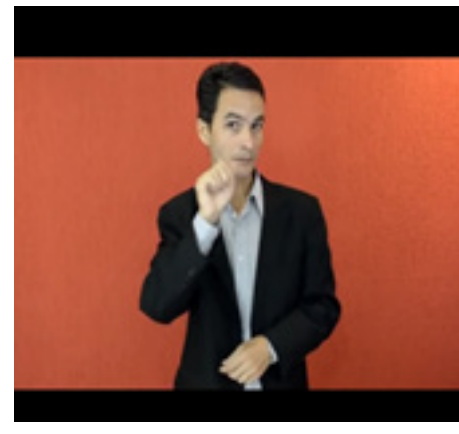

(a) Narrador explicando a história

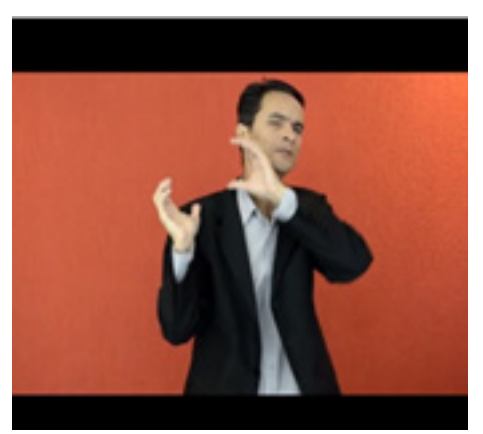

(b) Incorporação da mulher samaritana carregando um vaso ao ombro

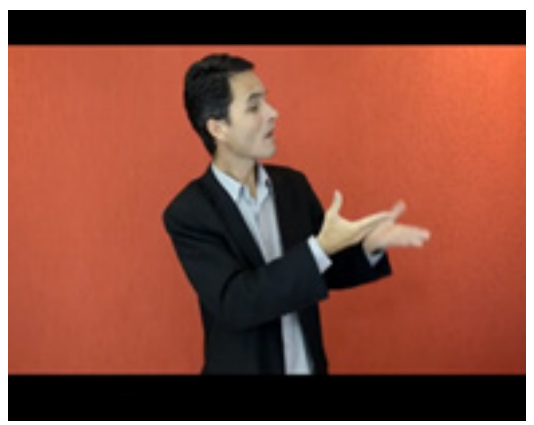

(c) Incorporação de Jesus conversando com a mulher

Fonte: Imagens do vídeo "A Mulher de Samaria", NONATO (2014), obtidas a partir do print de tela em 27 fev. 2018.

Outro vídeo analisado foi de uma piada narrada pelo surdo Andrei Borges, no qual ele conta sobre um voo que tem o combustível esgotado e em meio a tentativas de permanecer com o avião no ar, os ouvintes acabam caindo e o único sobrevivente é um surdo. Essa piada faz parte da literatura surda e mostra ironia com relação aos ouvintes - algo que é característico em piadas que envolvem surdos e ouvintes. Aspectos como mudança de di- 
A ação construída na libras conforme a linguística cognitiva

Elidéa Lúcia Almeida Bernardino - Dinalva Andrade Martins • Jéssica Cristina Borba de Moura • Stéfanie Veríssimo Bastos

recionamento do olhar do narrador (olhar para a câmera) para o personagem (olhar para dentro da cena) também foram percebidos nesse vídeo. E, além disso, o narrador identifica cada personagem, apresentando o seu sinal (ex.: PILOTO, HOMEM SURDO, HOMEM OUVINTE) antes de representá-lo utilizando a AC. Ele usa o recurso da inclinação do corpo apenas após indicar previamente os personagens envolvidos no diálogo. Identificamos 36 situações de AC na narrativa, que durou 2:44 minutos (Figura 5).

\section{Figura 5 - Imagens extraídas do vídeo "Piada do avião com um surdo e ouvintes", de Andrei Borges.}

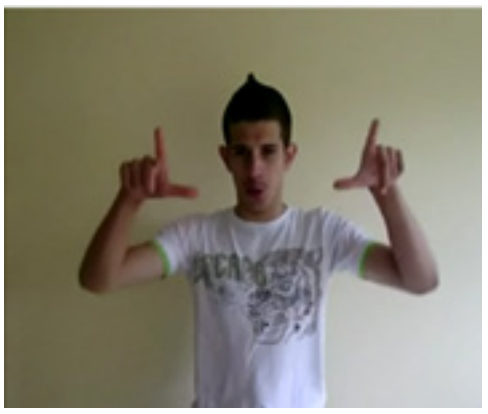

(a) Direcionamento do olhar do narrador para a câmera

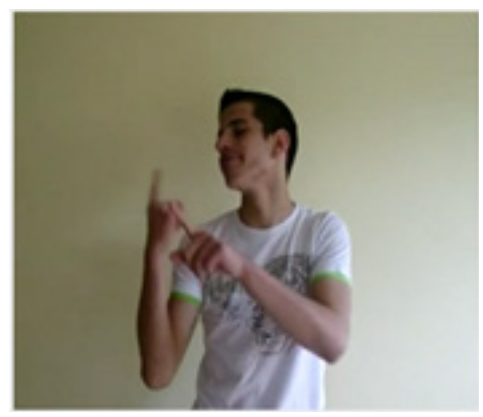

(b) Direcionamento do olhar do narrador observando o personagem ( $\mathrm{CL}, \mathrm{CM}$ "1")

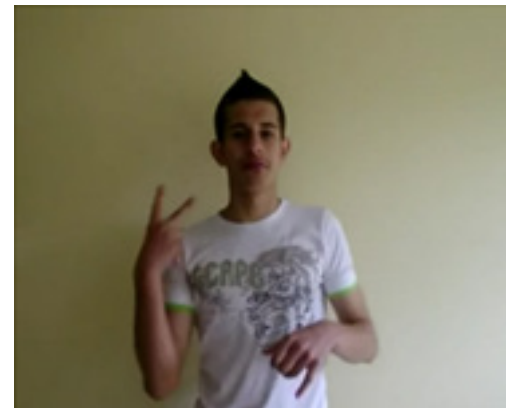

(c) Sinalização do personagem que será incorporado na cena seguinte (PILOTO)

Fonte: Imagens do vídeo "Piada do avião com um surdo e ouvintes", BORGES (2015), obtidas a partir do print de tela em 27 fev. 2018.

Buscando verificar a presença da AC em outros tipos de discursos, além de narrativas, analisamos alguns vídeos cotidianos, com um discurso mais casual. O próximo vídeo, um texto de opinião, "5 coisas que todo mundo gosta menos eu!", é do youtuber Léo Viturinno, que aborda aspectos da cultura surda, como identidade surda, cotidiano e curiosidades sobre a surdez. Nesse vídeo, o youtuber responde a uma pergunta de um de seus seguidores quanto às suas preferências.

Diversamente ao discurso narrativo, que descreve as ações de personagens, favorecendo o uso da AC, o texto de opinião analisado apresenta poucas situações em que a AC é utilizada. Nesse vídeo, percebemos que a AC se constrói de duas formas. Na pri- 
meira construção, o surdo incorpora o personagem para exemplificar as coisas que gosta de fazer, personificando a si próprio em algumas situações específicas. Suas expressões faciais e corporais se modificam e o olhar é voltado para dentro do cenário (para o espaço mental da narrativa), deixando de interagir com o interlocutor (a câmera, que se encontra no espaço mental real). Em alguns momentos, o sinalizante chega a fechar os olhos, como se voltasse o olhar para si mesmo. Na segunda construção, o sinalizante incorpora um personagem para exemplificar coisas que não gosta de fazer, como ficar se arrumando, se maquiando. O olhar é desviado da câmera e desfocado, as expressões facial e corporal nesse caso remetem a um estereótipo. Segundo Carvalho (2011):

\begin{abstract}
O termo estereótipo surgiu no século XX por meio de estudos das ciências sociais, nos quais definiu-se que "estereótipos são imagens prontas, que medeiam a relação do indivíduo com a realidade" (CHARAUDEAU; MAINGUENEAU, 2004, p.213). As áreas da psicologia e da sociologia definem que estereótipos são imagens cristalizadas e crenças pré-concebidas, que comumente apresentam concepções nocivas a indivíduos e grupos. Na área da linguística, o campo da semântica utiliza a ideia de estereótipo e o classifica como "ideia convencional associada a uma palavra" (Ibid., loc cit.). Para a Análise do Discurso, o estereótipo é conceituado como uma representação cristalizada, e está ligado ao dialogismo. (CARVALHO, 2011, p. 44).
\end{abstract}

O estereótipo é um "conceito que deve ser concebido como construído, imaginário e social" (CARVALHO, 2011, p. 44), ou seja, a partir da construção social que a nossa cultura tem em relação às pessoas, ideologias, entre outros conceitos. Assim, o sinalizante parte do estereótipo de como uma pessoa se maquia, e o utiliza na incorporação de um personagem (ver Figura 6). Identificamos esse tipo de incorporação como "Incorporação de Personagem - Estereótipo" e o sinalizante alterna os papéis de AC e de narrador. Nesse tipo de discurso analisado, a frequência de AC é menor que em 
A ação construída na libras conforme a linguística cognitiva

Elidéa Lúcia Almeida Bernardino - Dinalva Andrade Martins • Jéssica Cristina Borba de Moura • Stéfanie Veríssimo Bastos

textos narrativos. Em 3:47 minutos de vídeo, encontramos apenas nove situações de AC.

Figura 6 - Imagens extraídas do vídeo “5 coisas que todo mundo gosta, menos eu!", de Léo Viturinno.

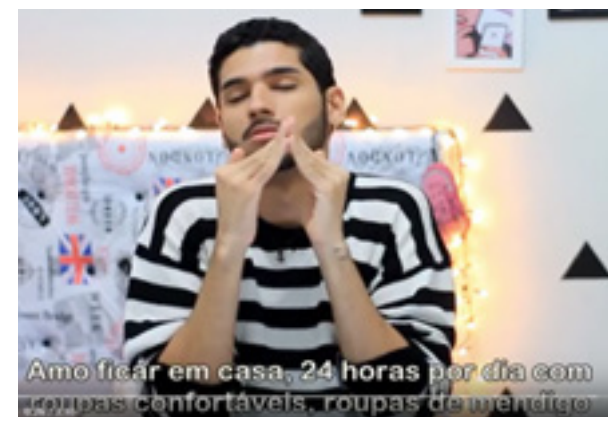

(a) Incorporação do personagem na narrativa

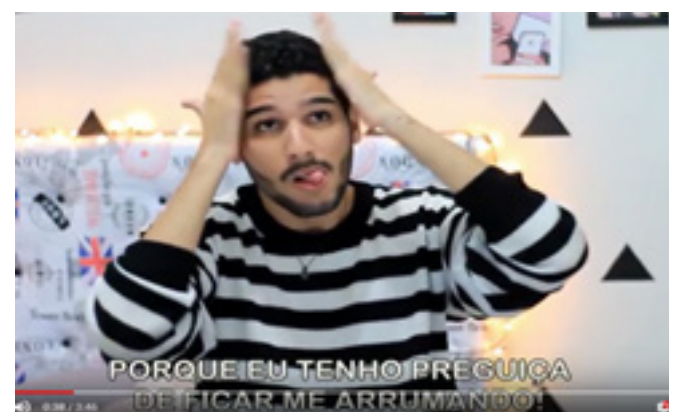

(b) Incorporação de personagem por meio de estereótipo

Fonte: Imagens do vídeo "5 coisas que todo mundo gosta, menos eu!", VITURINNO (2017), obtidas a partir do print de tela em 27 fev. 2018.

Outro vídeo analisado foi retirado de uma página do Facebook, chamada "A Sociedade em Libras", em que surdos de diversos lugares no mundo postam vídeos e outros textos sobre assuntos diversos em voga na atualidade. O vídeo selecionado é do Surdo Sandro Santos, que explica algumas terminologias do Direito, como "código penal", "estelionato" e "falso testemunho". Ele tem um objetivo didático de explicar alguns termos do Direito, buscando instruir surdos leigos no assunto. Para isso, ele utiliza um exemplo para cada terminologia.

Durante a explicação do termo, Sandro olha diretamente para a câmera, e quando exemplifica, ele se transforma nos vários personagens presentes nos seus exemplos, realizando ACs. Quando produz uma AC, incorporando um personagem, ele desvia o olhar da câmera, sua expressão facial se torna extremamente importante, uma vez que ele muda de um referente a outro apenas pelo uso das expressões corporais e faciais, mudando principalmente o direcionamento do olhar. Como o texto do vídeo é argumentativo, ocorrem flashes, momentos de incorporação de personagens, 
A ação construída na libras conforme a linguística cognitiva

Elidéa Lúcia Almeida Bernardino - Dinalva Andrade Martins • Jéssica Cristina Borba de Moura • Stéfanie Veríssimo Bastos

por isso o número de situações de AC é grande, pois são muitos momentos e curtos.

Nos textos analisados, a argumentação difere do texto narrativo, onde os momentos de incorporação do personagem são mais longos, o sinalizante demora mais tempo em uma AC. Nesse vídeo, quando o sinalizante alterna personagens durante um diálogo, muda apenas a expressão facial, direcionamento do corpo e olhar. Entretanto, como ele mantém a AC, só alternando os personagens, o seu olhar continua voltado para dentro da cena, para dentro do espaço mental do momento narrado, mas a mudança da direção desse olhar dentro do cenário marca a alteração dos personagens. Como a língua de sinais é espaço-visual, esse recurso facilita a referenciação. O espaço mental mapeado na cabeça do sinalizante é transferido para a sinalização, posicionando os personagens no espaço físico à sua frente. Exemplos retirados do vídeo são mostrados na Figura 7.

Figura 7 - Imagens extraídas do vídeo "Código penal Crime: cobrar dinheiro de pessoas Artigo 171 CP e artigo 342 ... surdo faltar consciência surdo.", de Sandro Santos.

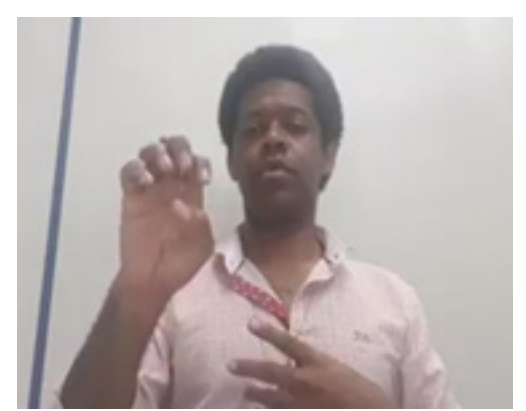

(a) Explicação sobre o Código Penal

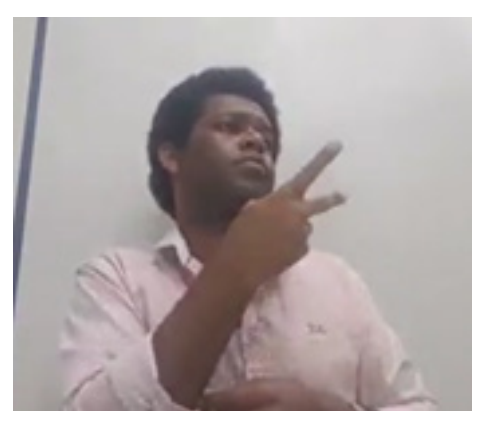

(b) Exemplo sobre Estelionato

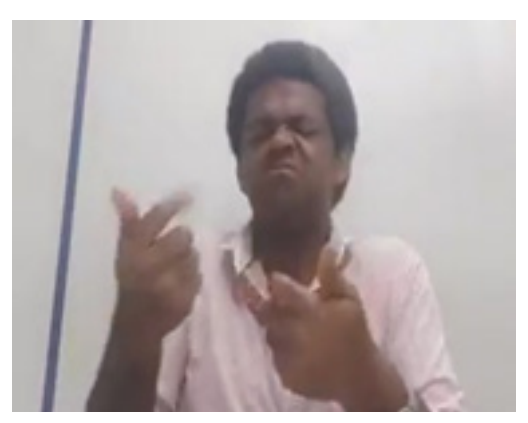

(c) Expressão Facial exaltada de um personagem

Fonte: Imagens do vídeo "Código penal Crime: cobrar dinheiro de pessoas Artigo 171 CP e artigo 342 ... surdo faltar consciência surdo.", SANTOS (2017), obtidas a partir do print de tela em 27 fev. 2018.

O vídeo tem duração de 11:06 minutos e foram identificadas 35 situações de AC. A análise foi feita a partir da mudança de direcionamento do olhar dentro da cena, quando era inserido um personagem no discurso. 
O vídeo "Gente que inspira" mostra uma entrevista da TV CES com Leonardo Castilho, arte educador no Museu de Arte Moderna de São Paulo. Castilho é ator e colabora com diversos projetos relacionados à arte e à surdez. Outro vídeo do mesmo autor é "Os surdos têm voz". Nesse segundo vídeo, Castilho apresenta algumas das dificuldades enfrentadas pelos surdos diante de atitudes inesperadas de ouvintes.

O vídeo "Os surdos têm voz" é narrativo, um testemunho onde o autor apresenta uma denúncia e na entrevista "Gente que inspira" há vários momentos em que Castilho utiliza AC para representar ações ou personagens, construindo momentos de narrativa e corroborando a ideia da importância da AC na construção visual das línguas de sinais.

Esses pontos podem ser observados em alguns exemplos a seguir (Figura 8):

\section{Figura 8 - Imagens extraídas dos vídeos “Os surdos têm voz" e "Gente que inspira", de Leonardo Castilho.}

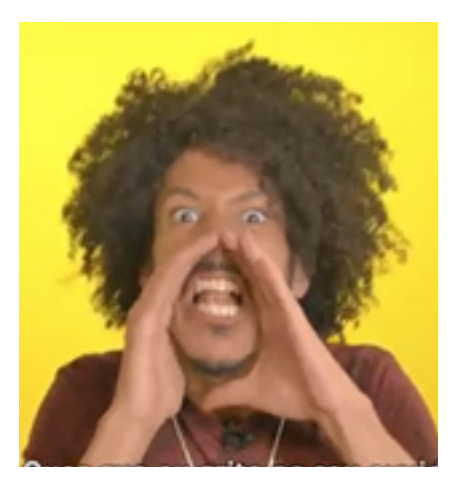

(a) Ação de gritar

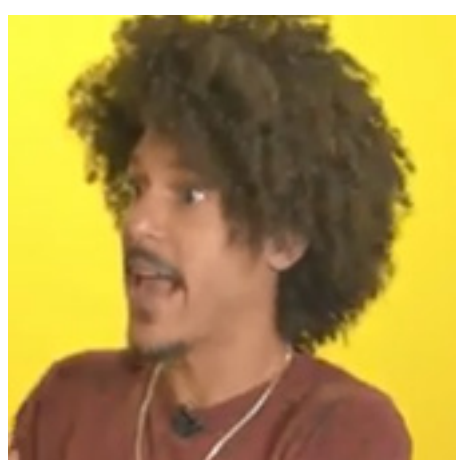

(b) Fala direta do personagem

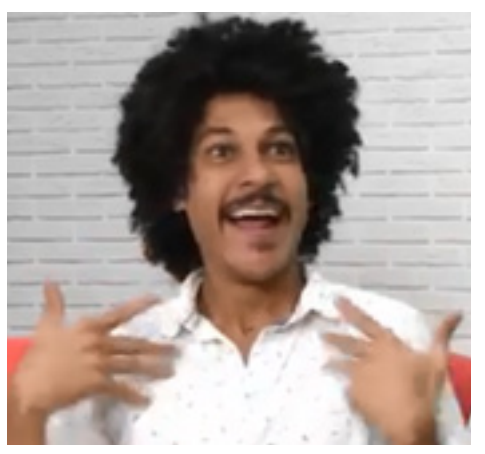

(c) Personificando um personagem feliz

Fonte: Imagens dos vídeos "Os surdos têm voz", CASTILHO (2017) e "Gente que inspira", CASTILHO (2016), obtidas a partir do print de tela em $27 \mathrm{fev} .2018$.

Na primeira imagem (a - ação de gritar), o rosto de Leonardo está virado para a câmera, mas parece ser um olhar para dentro da cena de uma pessoa gritando, uma vez que no vídeo ele é um narrador-personagem. Na segunda (b - fala direta do perso- 
A ação construída na libras conforme a linguística cognitiva

Elidéa Lúcia Almeida Bernardino - Dinalva Andrade Martins • Jéssica Cristina Borba de Moura • Stéfanie Veríssimo Bastos

nagem), quando ele relata um diálogo entre dois personagens, o olhar é claramente voltado para dentro da cena. Também na terceira imagem ( $c$ - quando Leonardo personifica um personagem feliz), o olhar é voltado para dentro da cena.

O olhar é uma característica muito importante na $A C$, pois marca a transição entre a incorporação de um personagem e a fala do próprio narrador. Essa característica pode ser percebida nas imagens apresentadas abaixo (Figura 9), em que o olhar para dentro da cena (a - retirando o foco da sua interlocutora) mostra a personificação de um personagem e, quando o olhar volta-se para a interlocutora (b), é o próprio Castilho falando com a entrevistadora.

Figura 9 - Imagens extraídas do vídeo "Gente que inspira”, de Leonardo Castilho.

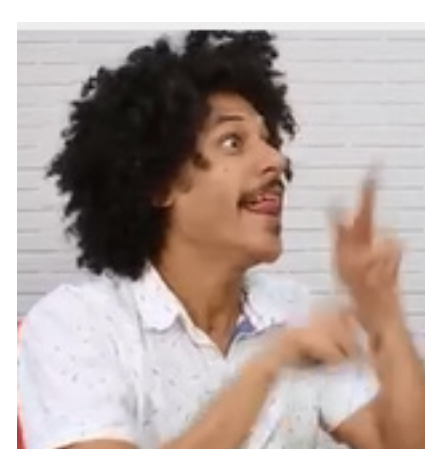

(a) Olhar para dentro da cena

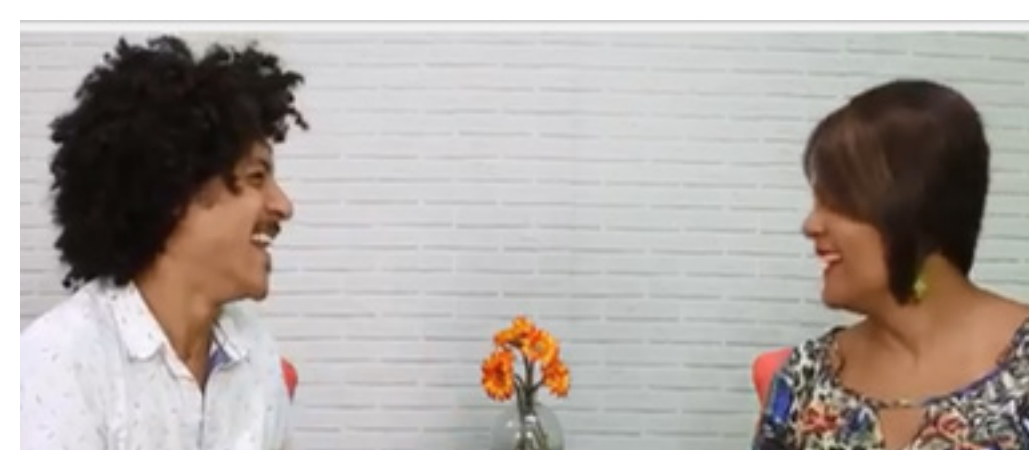

(b) Olhar voltado para o espaço mental real (interlocutora) Fonte: Imagem do vídeo "Gente que inspira", CASTILHO (2016), obtidas a partir do print de tela em 27 fev. 2018.

\section{Considerações finais}

Podemos perceber, nestes resultados apontados, que os espaços mentais são alterados à medida que o discurso se desenvolve. Isso ocorre tanto na narrativa quanto em outros momentos. $O$ espaço que fundamenta o discurso no momento de sua ocorrência seria a BASE, o espaço real onde os interlocutores se encontram 
e a partir dela os outros espaços mentais são criados para falar de outras informações que extrapolam o contexto imediato. Esses estudos corroboram a Teoria dos espaços mentais (FAUCONNIER, 1994, 1997 apud FERRARI, 2011), sendo que a AC, marcada pela direção do olhar, sinalizaria fisicamente a diferenciação dos espaços mentais, não somente no discurso do sinalizante, mas a AC deixa claro para o interlocutor os diferentes referentes.

Os resultados iniciais apontam que a AC é utilizada pelo sinalizante como uma estratégia linguística referencial, a fim de conduzir a atenção do interlocutor, por meio de recursos linguísticos visuais, para a cena desenvolvida através do discurso narrativo. Pela utilização da AC é possível conduzir o interlocutor para os diferentes espaços mentais criados e deixar as referências mais evidentes no discurso.

Na sinalização de uma história, o tempo da narrativa coincide com o espaço mental real, ou seja, o tempo presente, ou o tempo relativo à BASE (FERRARI, 2011). Ao utilizar uma AC, esse tempo torna-se histórico, coincidindo com o tempo relativo ao espaço mental da narrativa. Por exemplo, ao narrar uma história bíblica, como o primeiro exemplo apresentado (Rainer, Figura 4), quando assume o papel de narrador, o sinalizante refere-se ao tempo presente, o tempo da BASE, que é real, atual, mantendo contato visual com o seu interlocutor (ou a câmera). Quando o sinalizante incorpora um personagem através da $\mathrm{AC}$, o tempo cronológico ou o tempo histórico, assim como o tempo psicológico do referente narrado passam a ser o tempo da narrativa. Pela AC, o sinalizante transporta-se para o espaço mental do personagem, sendo que a direção do seu olhar irá marcar esse "transporte". Ao incorporar um referente, o sinalizante transmitirá em seu olhar, seu corpo, suas expressões faciais e corporais, as atitudes do seu referente incorporado.

É curioso observar que mesmo quando o sinalizante está incorporando o personagem, em alguns momentos (flashes de milésimos de segundo), ele lança o seu olhar para a câmera (ao espaço mental real) e volta em seguida ao espaço mental da cena 
narrada. Parece que nesses momentos o sinalizante mantém o personagem incorporado, mas com o lance do olhar assume novamente o seu papel de narrador - como parte da função fática da linguagem, interagindo e conectando-se com o seu interlocutor através do olhar, como se certificando de manter a atenção do interlocutor à narrativa, "visitando" de forma muito rápida o espaço mental real - e depois retorna mais uma vez ao espaço mental da narrativa. Isso ocorre várias vezes durante a narrativa, mas em momentos muito rápidos.

A construção de um palco narrativo é extremamente importante para a criação dos referenciais que serão parte do processo de construção dos personagens, a partir de duas perspectivas, uma externa e a outra interna (ÖZYÜREK; PERNISS, 2011; STEC, 2012). Na perspectiva externa, o sinalizante apresenta uma visão de fora da cena narrada, como um observador, e há uma interação mais direta com o interlocutor (PERNISS, 2007). Nas línguas de sinais, essa perspectiva é marcada pela utilização de classificadores. $\mathrm{Na}$ perspectiva interna, o sinalizante incorpora os personagens narrados e passa a fazer parte da cena, assumindo a perspectiva do personagem (PERNISS, 2007), gerando uma interação indireta com o interlocutor. Nessa perspectiva, o sinalizante utiliza a AC.

Além de marcar as perspectivas do personagem (ou perspectiva interna) e do observador (perspectiva externa), há momentos em que o sinalizante precisa apresentar ambas as perspectivas identificado na literatura como perspectiva mista - PERNISS (2007), dentre outros. Na prática, essa demarcação é feita utilizando AC e classificadores (DUDIS, 2006). Pelo fato de as línguas de sinais permitirem o uso de diferentes articuladores (cabeça, mãos e braços), o sinalizante tem o seu corpo particionado em diferentes áreas, sendo possível identificar diferentes referentes através do uso dos diferentes articuladores.

Como o sinalizante é o único elemento visível no espaço de sinalização, ele utiliza esses diferentes articuladores para identificar os diferentes espaços mentais criados na narrativa - seja a narrativa de uma história ou pequenas narrativas dentro de outros gê- 
neros textuais. A AC torna possível a identificação desses espaços mentais, tanto ao sinalizante quanto ao seu interlocutor. Alguns autores (QUINTO-POZOS, 2007b) sugerem que o uso desse recurso é obrigatório em certos momentos. Como pôde ser observado nesta pesquisa, a AC ocorre com mais frequência em narrativas, mas pode aparecer também em outros gêneros textuais.

\title{
Referências
}

\begin{abstract}
BERNARDINO, Elidéa L. A. O uso de classificadores na Língua de Sinais Brasileira. ReVEL, [s. I.], v. 10, n. 19, 2012. Disponível em: http://www. revel.inf.br/files/6ecf02602b4f746097e5749734cfd433.pdf. Acesso em: 16 fev. 2020.
\end{abstract}

BORGES, Andrei. Programa do surdo Andrei A viagem de avião.mp4 (vídeo público "baixado" do site de Andrei Borges em 09/10/2015) - não mais disponível na internet. Print de tela em 27/02/2018.

CARVALHO, Leonora Guiné de Mello. Estereótipo e identidade em piadas sobre o mineiro: uma perspectiva da análise do discurso. 2011. 80 f. Dissertação (Mestrado em Letras - Linguagem, Cultura e Discurso) - Departamento de Letras, Universidade Vale do Rio Verde, Três Corações, 2011. Disponível em: http://file:///G:/leonora_guine_de_mello_carvalho\%20Esteri\%C3\%B3tipo.pdf. Acesso em: 16 fev. 2018.

CASTILHO, Leonardo. Os surdos têm voz (vídeo). 20 jul. 2017. Disponível em: https://www.youtube.com/watch?v=Bcq6GPyMfPo. Acesso em: 27 fev. 2018.

CASTILHO, Leonardo. Gente que inspira - entrevista com o ator feita por Mirian Caxilé - TV CES (vídeo) 26 out. 2016. Disponível em: https:// www.youtube.com/watch?v=IZXuWpTsC4w. Acesso em: 27 fev. 2018. DUDIS, Paul G. Body partitioning and real-space blends. Cognitive Linguistics, [s. I.], v. 15, n. 2, p. 223-238, 2006. 
ELAN (Version 5.0) [Computer software]. Nijmegen: Max Planck Institute for Psycholinguistics, The Language Archive. Disponível em https://archive.mpi.nl/tla/elan Acesso em: 08 nov. 2017.

FERRARI, Lilian. Introdução à Linguística Cognitiva. São Paulo: Editora Contexto, 2011.

NONATO, Rainer. A mulher de Samaria (vídeo). 26 mar. 2014.

Disponível em: https://www.youtube.com/watch?v=0XrY5YeGgKw. Acesso em: 27 fev. 2018.

ÖZYÜREK, Aslı; ERNISS, Pamela. Event representation in sign language: A crosslinguistic perspective. In: BOHNEMEYER, Jürgen \& PEDERSON, E. (eds.), Event representation in language: Encoding events at the language-cognition interface. Cambridge: Cambridge University Press, 2011. p. 84-107.

PERNISS, Pamela M. Achieving spatial coherence in German Sign Language narratives: The use of classifiers and perspective. Lingua, [s. I.], v. 117, n. 7, p. 1315-1338, 2007.

QUINTO-POZOS, David. Can constructed action be considered obligatory? Urbana-Champaign, U.S. A. Lingua, [s. I.], v. 117, n. 7, p. 12851314, 2007a.

QUINTO-POZOS, David. Why does Constructed Action seem obligatory? An analysis of "Classifiers" and the lack of articulator-referent correspondence. Sign Language Studies, [s. I.], v. 7, n. 4, p. 458-506, Summer, 2007b. Disponível em: www.jstor.org/stable/26190713. Acesso em: 09 mar. 2016.

QUINTO-POZOS, David; PARRILL, Fey. Signers \& co-speech gestures adopt similar strategies for portraying viewpoint in narratives. Topics in Cognitive Science, [s. I.], v. 7, n. 1, p. 12-35, 2015.

SANTOS, Sandro. Código penal Crime: cobrar dinheiro de pessoas Artigo 171 CP e artigo 342 ... surdo faltar consciência surdo. Facebook: A Sociedade em Libras. 19 dez. 2017. Disponível em: https://www. facebook.com/sandro.pereira.56/videos/1573044019447835/ Acesso em: 27 fev. 2018. 
A ação construída na libras conforme a linguística cognitiva

Elidéa Lúcia Almeida Bernardino - Dinalva Andrade Martins • Jéssica Cristina Borba de Moura • Stéfanie Veríssimo Bastos

SILVA, Augusto Soares da; BATORÉO, Hanna Jakubowicz. Gramática Cognitiva: estruturação conceptual, arquitectura e aplicações.

Gramática Cognitiva, Portugal, p. 229-251, jan. 2010. Disponível em: http://ler.letras.up.pt/uploads/ficheiros/8319.pdf . Acesso em: 23 jan. 2018.

STEC, Kashmiri. Meaningful shifts: a review of viewpoint markers in co-speech gesture and sign language. Gesture, [s. I.], v. 12, n. 3, p. 327360, 2012.

SUPALLA, Ted. The classifier system in American Sign Language. In: CRAIG, Colette. (Ed.) Typological studies in language: noun classes and categorization. Amsterdam, Philadelphia: John Benjamin Publishing Company, 1986. Volume 7. p. 181-214.

TV CES. Gente que inspira - Leonardo Castilho (vídeo). 26 out. 2016. Disponível em: https://www.youtube.com/watch?v=IZXuWpTsC4w\&t=191s. Acesso em: 27 fev. 2018.

VITURINNO, Leonardo. 5 coisas que todo mundo gosta, menos eu! (vídeo). 2017. Disponível em: https://www.youtube.com/watch?v=L1mBOACGp-g\&t=41s . Acesso em: 27 fev. 2018. 